\title{
Lower respiratory tract symptoms in Queensland schoolchildren: risk factors for wheeze, cough and diminished ventilatory function
}

\author{
David L Duffy, Charles A Mitchell
}

\begin{abstract}
Background-The occurrence of respiratory symptoms and abnormal lung function in children is known to be influenced by genetic and many environmental factors. The association between specific respiratory symptoms in children of school age and their parents has been examined.
\end{abstract}

Methods-Respiratory symptoms and ventilatory function were recorded for 4549 schoolchildren in Queensland, Australia.

Results-The cumulative prevalence of wheezing was $23.1 \%$ of 8 year olds and $20.8 \%$ of 12 year olds, and the prevalence of wheezing within the previous 12 months was $13.9 \%$ and $10.5 \%$ respectively. A parental history of asthma or wheeze and hayfever was associated with wheeze in the child, but did not affect either the age of onset or frequency of episodes. A history of frequent cough in children who had never wheezed was associated with a parental history of frequent bronchitis, but less strongly with parental wheeze. These familial aggregations were not mediated by common exposure to cigarette smoke. Both a history of parental wheeze and maternal cigarette use were associated with a decrease in $\mathbf{F E F}_{25-75}$ in the child and these effects were additive.

Conclusions-The association of specific symptoms (wheeze and cough without wheeze) in parent and offspring is interpreted as evidence for different mechanisms of familial transmission, which may be genetic.

(Thorax 1993;48:1021-1024)

Asthma and other wheezy illnesses have a high prevalence in Australian children. ${ }^{1-3}$ Risk factors for childhood lower respiratory tract symptoms that have been previously described include family history, artificial feeding in the first few months of life, and exposure to cigarette smoke or allergens. ${ }^{4-6}$ In this paper we present an analysis of respiratory tract symptoms and lung function in Queensland schoolchildren, and examine relationships with a number of known potential risk factors.

\section{Methods}

The data collection procedures for this study have been described in detail elsewhere. ${ }^{1}$ During the period 1981-2, 4549 school children in years 3 (mean age 8.1 years) and 7 (12.1 years) attending 36 schools throughout the state of Queensland were surveyed for respiratory symptoms. A stratified random sample of schools with over 200 pupils was initially selected from 13 representative geographical areas. Consenting parents (usually the mothers) completed a 55 item questionnaire which sought details of the child's and family's medical history. This questionnaire had a high test-retest reliability, and its key items correlated well with spirometric abnormalities. ${ }^{1}$

All children were examined at a school visit by an observer blinded to the questionnaire results. Height and weight were recorded, and ventilatory function was measured by a Vitalograph dry wedge spirometer according to the recommended protocol of the American Thoracic Society. ${ }^{7}$ Forced expiratory volume in one second $\left(\mathrm{FEV}_{1}\right)$, forced vital capacity (FVC), and forced expiratory flow rate from $25 \%$ to $75 \% \mathrm{FVC}\left(\mathrm{FEF}_{25-75}\right)$ were derived from the best (highest $\mathrm{FEV}_{1}$ ) of three reproducible curves.

Analyses of the data were performed by multiple logistic regressions using SPSS-PC, ${ }^{8}$ SAS $6 \cdot 07,{ }^{9}$ and GLIM 3.77. ${ }^{10}$ Two outcome variables were used. The first was frequent wheezing (one or more episodes of wheeze in every three month period during the last two years), defining wheeze as an affirmative answer to the question "has he/she at any time in his/her life suffered from attacks of asthma or wheezy breathing?". The second outcome variable was frequent cough in children who had never wheezed. The presence of the symptom of productive cough was diagnosed by response to the item "has he/she at any time in his/her life suffered from bronchitis or attacks of cough with sputum (phlegm) in the chest ('loose' or 'rattly' cough)?". Symptom frequency of both was recorded on an eight point scale from "no attacks in the last two years" to "about once in 24 hours".

The risk factors entered into the regression were maternal and paternal wheezing, bronchitis, hayfever and smoking, age and race of the child (Aboriginal or non-Aboriginal), breast feeding in the first three months of life, 
contact with animals (cats, dogs, birds and livestock), and whether bedrooms were shared or not. Parental wheezing was defined as a positive response to the item "has she/he at any time in his/her life suffered from attacks of asthma or wheezy breathing?"; parental bronchitis as a positive response to the item "does he/she suffer from chronic bronchitis (attacks of cough with sputum (phlegm) in the chest), or from more than one attack of bronchitis every three years or so?" and excluding those parents who also reported a history of wheeze. The item "has he/she at any time in his/her life suffered from hay fever"-elsewhere defined as "sneezing, running or blocked nose, sometimes with itchy eyes or nose"-was used to diagnose parental hayfever or allergic rhinitis. Parental cigarette use was recorded on a five point scale: $0,1-5$, $6-10,11-20,>20$ cigarettes per day.

\section{Results}

A total of 4549 (2360 from year 3 and 2189 from year 7) out of 4819 eligible students took part in the study, a participation rate of $\mathbf{9 4 . 4 \%}$. School medical records revealed no differences in the prevalence of previously diagnosed asthma among non-responders and responders ( $3.4 \%$ in each). There were 2336 males and 2213 females in the study. Aboriginal students comprised 151 of the subjects.

\section{WHEEZING}

The lifetime prevalence of wheezing was $23.1 \%$ among the 8 year old children and $20.8 \%$ among the 12 year olds, and wheezing in the previous 12 months was $13.9 \%$ and $10.5 \%$ respectively $\left(\chi_{1}^{2}=12 \cdot 1, \mathrm{p}<0.001\right)$. The male:female ratio among those who had ever wheezed was 1.4 at both ages. Frequent wheezing (one or more episodes per three months) was reported in $8 \cdot 1 \%$ of 8 year olds and $5.6 \%$ of 12 year olds.

For frequent wheeze (table 1) maternal wheeze was the strongest risk factor, significantly more so than paternal wheeze. Frequent wheeze was also independently

Table 1 Risk factors associated with report of wheeze occurring once every three months or more often. Reference group for odds ratios is children reported to have never suffered respiratory symptoms

\begin{tabular}{|c|c|c|c|}
\hline Risk factor & $\begin{array}{l}\text { Adjusted } \\
\text { odds ratio }\end{array}$ & $\begin{array}{l}95 \% \text { confidence } \\
\text { interval }\end{array}$ & $\begin{array}{l}\text { Wald test } \\
p \text { value }\end{array}$ \\
\hline Age (years) & 0.87 & $0.81,0.94$ & 0.00 \\
\hline Maternal wheeze & $4 \cdot 13$ & $2 \cdot 89,5 \cdot 91$ & 0.00 \\
\hline Paternal wheeze & $2 \cdot 37$ & $1.63,3.45$ & 0.00 \\
\hline Maternal bronchitis & $3 \cdot 44$ & $1.99,5 \cdot 97$ & 0.00 \\
\hline Paternal bronchitis & $3 \cdot 34$ & $2 \cdot 05,5 \cdot 42$ & 0.00 \\
\hline Maternal hayfever & $1 \cdot 71$ & $1 \cdot 23,2 \cdot 37$ & 0.00 \\
\hline Paternal hayfever & 1.67 & $1 \cdot 19,2 \cdot 34$ & 0.00 \\
\hline Male sex & 1.68 & $1 \cdot 24,2 \cdot 28$ & 0.00 \\
\hline $\begin{array}{l}\text { Breast feeding (first } \\
\text { three months of life) }\end{array}$ & $1 \cdot 25$ & $0.91,1.70$ & $0 \cdot 16$ \\
\hline Race (Aboriginality) & 0.98 & $0.52,1.84$ & 0.94 \\
\hline Sharing a bedroom & 0.94 & $0 \cdot 79,1 \cdot 19$ & 0.75 \\
\hline Maternal smoking ${ }^{\star}$ & $1 \cdot 11$ & $0.99,1 \cdot 25$ & 0.06 \\
\hline Paternal smoking ` & 0.98 & $0.89,1.08$ & 0.62 \\
\hline Contact with cat(s) & 0.84 & $0 \cdot 62,1 \cdot 13$ & 0.25 \\
\hline
\end{tabular}

* Smoking treated as an interval variable ranging from 1 (non-smoker) to 5 (>20 cigarettes per day). related to maternal and paternal bronchitis, and to hayfever in either parent. The pattern of predictors was similar in models with "ever" wheezing and the combination of wheeze and hayfever in the child (data not shown).

Overall, mothers were more likely to report wheeze than fathers $(21 \% v 16 \%, \mathrm{p}<0.001)$, and smoking parents were more likely to report suffering hayfever, wheezing, or both. Smokers were more likely to be married to a smoker, but this did not fully explain the observed correlation of respiratory symptoms between parents since this association was also seen in non-smoking families.

For children who had ever wheezed, neither the total number, frequency of episodes, and age of onset of wheeze was affected by the number of parents (none, one or both) reported to wheeze-that is, although the presence or absence of wheeze was associated with parental history, the latter had no such effect on severity (table 2 ).

PRODUCTIVE COUGH

The lifetime prevalence of non-wheezy cough was $33 \%$ among the 8 year olds and $28 \%$ among the 12 year olds. Frequent nonwheezy cough was reported for $4.5 \%$ of the 8 year olds and $2 \cdot 3 \%$ of the 12 year olds. The major predictor of frequent non-wheezy cough was maternal bronchitis (table 3 ), significantly stronger than paternal bronchitis or asthma in either parent. Parental hayfever, in contrast to wheeze in the child, was not significantly associated. Parental cigarette use was not significantly associated with frequent cough in the child, but predictably was strongly associated with parental bronchitis. "Ever" cough in the child was weakly associated with parental hayfever and maternal, but not paternal, smoking.

There was an association between the number of parents with a history of bronchitis and frequency of cough in the child (table 4), but not for age of onset. No modulating effect of the number of parents with a history of asthma/wheezing on frequency of cough was observed.

VENTILATORY FUNCTION

There was no effect of history of parental

Table 2 Frequency of episodes of wheeze in children tabulated by number of natural parents with past history of asthma or wheezing (trend $\chi^{2}{ }_{1}=1 \cdot 15, p=0 \cdot 28$ )

\begin{tabular}{|c|c|c|c|}
\hline & \multicolumn{3}{|c|}{ Number of affected parents } \\
\hline & None & One & Both \\
\hline Ever wheeze & $396[15 \cdot 4]^{\star}$ & $358[35 \cdot 9]$ & $81[47 \cdot 1]$ \\
\hline $\begin{array}{l}\text { One or more } \\
\text { attack per } \\
\text { month }\end{array}$ & $46(11 \cdot 6) \dagger$ & $54(13 \cdot 2)$ & $10(10 \cdot 9)$ \\
\hline $\begin{array}{l}\text { One attack per } \\
3-12 \text { months }\end{array}$ & $132(33 \cdot 3)$ & $121(33 \cdot 8)$ & $29(35 \cdot 8)$ \\
\hline $\begin{array}{l}\text { Less than one } \\
\text { attack per year }\end{array}$ & $218(55 \cdot 0)$ & $183(51 \cdot 1)$ & $42(51 \cdot 8)$ \\
\hline
\end{tabular}

*Square brackets denote percentage of all children from mating type (unaffected $x$ unaffected, affected $\times$ unaffected, or affected $\times$ affected); $\dagger$ parentheses denote percentage of affected offspring of mating type. 
Table 3 Risk factors associated with report of cough occurring once every three months or more often without a history of wheeze. Reference group for odds ratios is children reported to have never suffered respiratory symptoms

\begin{tabular}{llll}
\hline Risk factor & $\begin{array}{l}\text { Adjusted } \\
\text { odds ratio }\end{array}$ & $\begin{array}{l}95 \% \text { confidence } \\
\text { interval }\end{array}$ & $\begin{array}{l}\text { Wald test } \\
\text { p value }\end{array}$ \\
\hline Age (years) & 0.83 & $0 \cdot 75,0.91$ & 0.00 \\
Maternal wheeze & 3.14 & $1 \cdot 85,5 \cdot 33$ & 0.00 \\
Paternal wheeze & 1.81 & $1.05,3 \cdot 12$ & 0.03 \\
Maternal bronchitis & 7.85 & $4.40,14.01$ & 0.00 \\
Paternal bronchitis & 3.28 & $1.80,5.98$ & 0.00 \\
Maternal hayfever & 0.90 & $0.56,1.44$ & 0.66 \\
Paternal hayfever & 1.38 & $0.85,2.23$ & 0.20 \\
Male sex & 1.12 & $0.75,1.67$ & 0.57 \\
Breast feeding (first & & & \\
three months of life) & 1.37 & $0.91,2.07$ & 0.14 \\
Race (Aboriginality) & 0.87 & $0.37,2.05$ & 0.75 \\
Sharing a bedroom & 1.16 & $0.89,1.50$ & 0.27 \\
Maternal smoking & 1.03 & $0.88,1.19$ & 0.74 \\
Paternal smoking & 1.01 & $0.89,1.15$ & 0.86 \\
Contact with cat(s) & 0.84 & $0.62,1.13$ & 0.25 \\
\hline
\end{tabular}

*Smoking treated as an interval variable ranging from 1 (non-smoker) to 5 (>20 cigarettes per day).
Table 4 Frequency of episodes of productive cough (without wheeze) tabulated by parents' history of bronchitis (trend $\chi^{2}{ }_{1}=14 \cdot 1, p<0.001$ )

\begin{tabular}{llll}
\hline & \multicolumn{3}{l}{ Number of affected parents } \\
\cline { 2 - 4 } & None & One & Both \\
\hline $\begin{array}{l}\text { Ever cough } \\
\begin{array}{l}\text { More than one } \\
\text { attack per year }\end{array}\end{array}$ & $908[27 \cdot 4]^{\star}$ & $178[47 \cdot 1]$ & $31[59 \cdot 6]$ \\
$\begin{array}{l}\text { Less than one } \\
\text { attack per year }\end{array}$ & $669(73 \cdot 7)$ & $107(60 \cdot 1)$ & $19(58 \cdot 1)$ \\
\hline
\end{tabular}

*Square brackets denote percentage of all offspring of mating type (unaffected $x$ unaffected, affected $x$ unaffected, affected $\times$ affected); tparentheses denote percentage of affected offspring of mating type.

wheeze, bronchitis, hayfever or cigarette use on $\mathrm{FEV}_{1}$, but significant effects were found on $\mathrm{FEF}_{25-75}$ (table 5). Maternal wheezing was associated with diminished $\mathrm{FEF}_{25-75}$ in both male and female offspring. By contrast, paternal wheezing was only significantly associated with decreased $\mathrm{FEF}_{25-75}$ in male offspring. Parental hayfever was not a significant predictor of lower FEF $_{25-75}$.

The effect of maternal smoking was additive to a history of maternal wheeze. Paternal smoking did not seem directly to influence lung function.

\section{Discussion}

The cumulative prevalence of wheeze seen in our study is similar to that reported in

Table 5 Adjusted effects on forced expiratory flow rate from $25 \%$ to $75 \%$ forced vital capacity $\left(F E F_{25-75}\right)$ of parental history of wheeze, bronchitis, and smoking (an interval variable ranging from 1 (non-smokers) to 5 (>20 cigarettes per day))

\begin{tabular}{lrrl}
\hline & $\begin{array}{l}\text { Adjusted } \\
\text { effect } \\
(\mathrm{ml} / \mathrm{s})\end{array}$ & $\begin{array}{l}\text { 95\% confidence } \\
\text { limits }\end{array}$ & p value \\
\hline Misk factor & -78 & $-127,-29$ & 0.00 \\
Maternal wheeze & -65 & $-117,-13$ & 0.01 \\
Maternal wheeze & -102 & $-178,-26$ & 0.01 \\
Paternal bronchitis & -62 & $-127,+03$ & 0.06 \\
Maternal smoking & -20 & $-34,-05$ & 0.00 \\
Paternal smoking & +4 & $-8,+15$ & 0.54 \\
\hline
\end{tabular}

*Adjusted for height, height ${ }^{2}$, weight, weight ${ }^{2}$, height $\times$ weight, age, age ${ }^{2}$, sex, sex $\times$ height, sex $\times$ weight, sex $\times$ age. other Australian, ${ }^{1-31112}$ New Zealand, ${ }^{13}$ and British $^{513-15}$ surveys. The higher lifetime cumulative prevalence in the 8 year olds than in the 12 years olds in our study might suggest a cohort effect, but is more likely to result from a failure of parents to recall mild wheezing in the early life of the older children. The prevalence of recent wheezing was significantly lower than that found recently in Australian schoolchildren. ${ }^{2}$

Both asthma and hayfever are diseases with a strong genetic component. ${ }^{16} 17$ The findings of our study were consistent with this: both parental asthma and hayfever were independently associated with wheeze and diminished lung function $\left(\mathrm{FEF}_{25-75}\right)$. The greater effect of a history of maternal than paternal wheezing may reflect bias as the questionnaire was usually completed by the mother, and females are more likely to report health problems than males. ${ }^{1518}$ If mothers of asthmatic children were more likely to recall wheezy illnesses in their past than the mothers of non-wheezy children, this would lead to a spuriously greater association. An alternative biological explanation would involve environmental or genetic $^{19}$ effects shared by the child and mother to a greater extent than with the father.

Our findings in children reporting episodes of productive cough without wheeze are more novel. Children who suffer multiple episodes of lower respiratory symptoms early in childhood have diminished lung function and velocity of growth of lung function with age ${ }^{20}$ and are at increased risk of lung diseases such as chronic bronchitis in adulthood. ${ }^{1421}$

A history of "non-wheezy" cough was more common in the offspring of parents who reported frequent bronchitis, with a gradient of disease severity dependent on the number of parents affected. This suggests either polygenic inheritance, or exposure to a common aetiological agent(s), or both. Such a familial tendency to chronic productive cough as distinct from that to asthma has been suggested in other community based studies ${ }^{22} 23$ and might conceivably be predicted from the increased incidence of minor (genetically determined) immunodeficiencies seen in such children referred for specialist assessment. ${ }^{24} 25$ A recent report has suggested the presence of a major gene affecting pulmonary function segregating in the families of probands with chronic obstructive lung disease. ${ }^{26}$ It should be noted that parental bronchitis did predispose to wheeze in the child, but to a lesser extent than a history of parental wheeze. Wheezing in the child, irrespective of the presence or absence of productive cough, was associated with a similar history in the parent but with no gradient of severity of affectation with respect to parental history. This suggests a simple mode of inheritance such as autosomal dominant with incomplete penetrance ${ }^{17}$ where severity of disease is presumably modulated by environmental factors. This is in agreement with the results of a recently reported longitudinal study of childhood asthma. ${ }^{27}$ 
Leeder and coworkers, ${ }^{4}$ analysing similar data in younger children, chose not to exclude wheezing from their definition of parental bronchitis. They found that parental "cough phlegm" was not associated with infant pneumonia or bronchitis after the effect of parental "asthma wheeze" (a strong predictor) was allowed for. As in our study they noted a marital correlation between symptoms reported for each parent, but thought this could be explained by the parallel correlation of smoking habits. The absence of a significant association between parental smoking and wheeze or cough in the children in our study has been described in several large studies of school age children. ${ }^{28} 29$

An effect of parental smoking on children's lung function has been reported in several previous studies. ${ }^{30-32}$ As in our study, Kauffmann and coworkers ${ }^{31}$ found that maternal smoking had a greater effect than paternal smoking and was best detected by its effect on FEF $_{25-75}$. This maternal effect is presumably due to the child's greater duration and intensity of exposure to smoke from the mother's cigarette.

Cigarette smoke and family history of lung disease were additive in their effect on lung function, although these factors explain a small proportion of variation in lung function. Other genetic factors would explain a large proportion of the residual variation. ${ }^{33} 34$

In cross sectional studies the conclusions are contingent on the reliability of recalled information. We have already noted that this may explain some inconsistencies in the relationships between symptoms in the child and in the parents. However, the correlations between reported symptoms and lung function in the children, and especially the presence of dose-response relationships between frequency of symptoms and $\mathrm{FEF}_{25-75}$, present strong evidence of the validity of the reported data while the reliability of questionnaire items over two months was also high. ${ }^{1}$

In conclusion, we have confirmed a number of previously reported risk factors for childhood respiratory symptoms but have found that wheeze or cough in children are associated with different symptoms in the parents. These findings are consistent with the hypothesis that wheeze and cough in children may have different aetiologies.

This work was supported by the Lions Research Foundation. DLD is supported by the Asthma Foundation of Queensland and receives an NH \& MRC PHRD Medical Postgraduate Scholarship.

1 Mitchell C, Miles J. Lower respiratory tract symptoms in Queensland schoolchildren. The questionnaire: its reliability and validity. Aust NZ $\mathcal{Y}$ Med 1983;13:264-9.

2 Robertson CF, Heycock E, Bishop J, Nolan T, Olinsky A Phelan P. Prevalence of asthma in Melbourne schoolchildren: changes over 26 years. BMF 1991;302:1116-8.

3 Salome CM, Peat JK, Britton WJ, Woolcock AJ. Bronchial hyperresponsiveness in two populations of Australian schoolchildren. I. Relation to respiratory symptoms and diagnosed asthma. Clin Allergy 1987; 17:271-81.

4 Leeder SR, Corkhill R, Irwig LM, Holland WW. Influence of family factors on the incidence of lower respiratory illness during the first year of life. $\mathrm{Br} \mathcal{F}$ Prev Soc Med 1976;30:203-12

5 Leeder SR, Corkhill R, Irwig LM, Holland WW. Influence of family factors on the incidence of asthma and wheezing during the first five years of life. $B r f$ Prev Soc Med 1976;30:213-8.

6 Sherman CB, Tosteson TD, Tager IB, Speizer FE, Weiss ST. Early childhood predictors of asthma. Am $\mathscr{f}$ Epidemiol 1990;132:83-95.

7 American Thoracic Society. ATS statement: Snowbird workshop on standardisation of spirometry. $A m$ Rev Respir Dis 1981;123:124.

8 Norušis MJ. SPSS-PC: Introductory statistics guide. Chicago: SPSS, 1986

9 SAS Institute. SAS language and procedures: usage, version 6. Cary, North Carolina: SAS Institute, 1989.

10 Numerical Algorithms Group of the Royal Statistical Society. The GLIM system release 3.77 manual Oxford: Numerical Algorithms Group, 1986.

11 Gibson HB, Silverstone H, Gandevia B. Respiratory disorders in seven-year-old children in Tasmania. Aims, methods and administration of the survey. Med $\mathcal{F}$ Aust 1969;2:201-5.

12 Williams $\mathrm{H}, \mathrm{McNichol} \mathrm{KN}$. Prevalence, natural history, and relationship of wheezy bronchitis and asthma in children. An epidemiological study. BMF 1969;iv: 321-5.

13 Barry DMJ, Burr ML, Limb ES. Prevalence of asthma among 12 year old children in New Zealand and South Wales: a comparative survey. Thorax 1991;46:405-9.

14 Strachan DP, Anderson HR, Bland JM, Peckham C. Asthma as a link between chest illness in childhood and $\infty$ chronic cough and phlegm in young adults. $B M Y$. 1988;296:890-3.

15 Clifford RD, Radford $M$, Howell JB, Holgate ST, Prevalence of respiratory symptoms among 7 and 11 year old schoolchildren and association with asthma Arch Dis Child 1989;64:1118-25.

16 Edfors-Lub M-L. Allergy in 7000 twin pairs. Acta Allergol 1971;26:249-85.

17 Cookson WOCM, Faux JA, Sharp PA, Hopkin JM. Linkage between immunoglobulin $\mathrm{E}$ responses underlying asthma and rhinitis and chromosome 11q. Lancet $1989 ; \mathrm{i}: 1292-4$.

18 Marsh DG, Meyers DA, Bias WB. The epidemiology and genetics of atopic allergy. $N$ Engl $f$ Med 1981;305: $\omega$
$1551-9$.

19 Sandford AJ, Shirakawa T, Moffatt MF, Daniels SE, Ra C, Faux JA, et al. Localisation of atopy and $\beta$ subunit of high-affinity IgE receptor (FcERI) on chromosome 11q. Lancet 1993;341:332-4.

20 Gold DR, Tager IB, Weiss ST, Tosteton TD, Speizer FE Acute lower respiratory illness in childhood as a predictor of lung function and chronic respiratory symptoms. Am Rev Respir Dis 1989;140:877-84.

21 Speizer FE, Tager IB. Epidemiology of chronic mucus hypersecretion and obstructive airway disease. Epidemiol Rev 1979;1:124-42.

22 Higgins M, Keller J. Familial occurrence of chronic respiratory disease and familial resemblance in ventilatory capacity. f Chronic Dis 1975;28:239-51.

23 Tager IR, Rosner B, Tishler PV, Speizer FE, Kass EH. Household aggregation of pulmonary function and chronic bronchitis. Am Rev Respir Dis 1976;114:485-92.

24 Smith TF, Morris EC, Bain RC. IgG subclasses in nonallergic children with chronic chest symptoms. F Pediatr 1984;105:896-900.

25 Beard LJ, Maxwell GM, Thong YH. Immunocompetence of children with frequent respiratory infections. Arch Dis Child 1981;56:101-5.

26 Rybicki BA, Beaty TH, Cohen BH. Major genetic mechanisms in pulmonary function. $f$ Clin Epidemiol 1990; 43:667-75.

27 Roorda RJ, Gerritsen J, Van Aalderen WMC, Knol K. Influence of a positive family history and associated allergic diseases on the natural course of asthma. Clin Exp Allergy 1992;22:627-34.

28 Bland M, Bewley BR, Pollard V, Banks MH. Effect of children's and parents' smoking on respiratory symp- $\sigma$ toms. Arch Dis Child 1978;53:100-5.

29 Lebowitz MD, Burrows B. Respiratory symptoms related $\varphi$ to smoking habits of family adults. Chest 1976;69: $48-50$.

30 Hosein $\mathrm{HR}$, Corey $\mathrm{P}$, Robertson J McD. The effect of domestic factors on respiratory symptoms and $\mathrm{FEV}_{1}$. Int f Epidemiol 1989;18:390-6.

31 Kauffmann F, Tager IB, Munoz A, Speizer FK. Familial factors related to lung function in children aged 6-10 years. Results from the PAARC epidemiologic study, 8 Am f Epidemiol 1989;129:1289-99.

32 Rona RJ, Chinn S. Lung function, respiratory illness, and passive smoking in British primary school children. Thorax 1993;48:21-5.

33 Gibson JB, Martin NG, Oakeshott JG, Rowell DM. Lung function in an Australian population: contribution of $\underline{\overrightarrow{0}}$ polygenic factors and the $P i$ locus to individual differences in lung function in a sample of twins. Ann Hum Biol 1983;10:547-56.

34 Redline S, Tishler PV, Lewitter FI, Tager IB, Munoz A Speizer FE. Assessment of genetic and nongenetic influences on pulmonary function. Am Rev Respir Dis 1987 135:217-22. 